\title{
3D kinematic analysis of patients' gait before and after unilateral total hip replacement
}

\author{
KATEŘINA KOLÁŘOVÁ ${ }^{1}$, TOMÁŠ VODIČKA ${ }^{1 *}$, MICHAL BOZDĚCH ${ }^{1}$, MARTIN REPKO $^{2}$ \\ ${ }^{1}$ Department of Kinesiology, Faculty of Sports Studies, Masaryk University, Brno, Czech Republic. \\ ${ }^{2}$ Department of Orthopedic Surgery, Faculty Hospital Brno - Adult Age Medicine, Brno, Czech Republic.
}

\begin{abstract}
Purpose: The purpose of the study was to describe changes in the kinematic parameters in the patients' gait after total hip replacement. Methods: Research group of men in the end stage of osteoarthritis indicated to the THR $(n=10$; age $54.1 \pm 7.5$ years; weight $92.2 \pm 9.6 \mathrm{~kg}$; height $179.7 \pm 5.9 \mathrm{~cm}$ ). All participants underwent a total of three measurements: before surgery, 3 and 6 months after the surgery. Using the 3D kinematic analysis system, the patients' gait was recorded during each measurement session and kinematic analysis was carried out. The parameters that were monitored included the sagittal range of motion while walking in the ankle, the knee and the hip joints of the operated and the unoperated limb, and the range in the hip joint's frontal plane, the rotation of pelvis in the frontal and transverse planes, as well as the speed of walking and the walking step length. Results: Significant increases were found in sagittal range of motion in the operated hip joint, sagittal range of motion in the ankle joint on the unoperated side and in the walking step length of the unoperated limb. Conclusions: During walking after a THR, the sagittal range of motion in the ankle of the unoperated limb increases. Also, the range of motion in the sagittal plane on the operated joint increases, which is related to the lengthening of the step of the unoperated lower limb.
\end{abstract}

Key words: hip joint, arthrosis, THR, 3D kinematics, gait analysis

\section{Introduction}

Endoprostheses of weight-bearing joints currently rank among the most widely performed surgical procedures in orthopaedic practice [7]. The number of surgical interventions has been increasing mainly because of the development of civilization and lifestyle diseases. Unhealthy eating habits, insufficient joint loading or, conversely, excessive joint loading as a result of obesity or inappropriate sporting activity, injury and longer use of the joint with the continuing increase in average life expectancy - these are the factors contributing to the degenerative processes in the joint and its consequent arthrosis. About $60 \%$ of the population between the ages of 55 and 64 and as many as $90 \%$ between 75 and 84 years of age suffer from arthrosis [11].
A large number of studies comparing the kinematic parameters of healthy persons' gait with the gait of patients with advanced arthrosis report significant differences in the walking mechanics between the two groups. In general, patients suffering from arthrosis were observed to walk more slowly [5], with smaller step lengths [16] and a longer relative time of the double limb stance [5]. Differences were found in frontal and sagittal range of motion (ROM) in the hip joints [5] and in the ankle joints [16] or in rotations of the pelvis and trunk in the transverse plane [21].

Problems and pains in the hip joint can lead to a considerable loss of a person's mobility and selfreliance [7]. Treatment can include the use of pharmaceuticals and conservative interventions, however in many cases the best solution is total hip replacement (THR) [12]. In majority of the cases, the operation brings subjective improvement in the patient's state

\footnotetext{
* Corresponding author: Tomáš Vodička, Department of Kinesiology, Faculty of Sports Studies, Masaryk University, Brno, Czech Republic. E-mail: tvodicka@fsps.muni.cz

Received: January 8th, 2020

Accepted for publication: April 28th, 2020
} 
and quality of life [8], [15]. However, the gait biomechanics of patients after THR and that of healthy people still considerably differs in hips and knees ROM [2] and its loading [1], [19], in moments of force [4] and activity of the hip muscles [9] or in rotations of the pelvis [10], [18].

The success rate of the treatment of patients for whom THR is indicated depends on many factors concerning the operation itself [3], [10], [17], the post-operative care and the general condition of the patient [2], [14].

The purpose of the work was to evaluate the development of changes in the kinematic parameters of the patients' gait after THR and identifying the possible linkage between these changes. As a consequence of the gait pattern improvement we generally expect:

i) increased ranges of motion in hips, knees and ankles,

ii) longer steps,

iii) reduced pelvis rotations in the post-surgery process.

\section{Materials and methods}

\section{Participants}

Participants in our study were randomly selected from among patients suffering from osteoarthrosis at stages III-IV according to the Kellgren-Lawrence classification, without any signs of dysplasia, operated at the First Department of Orthopaedic Surgery at the Saint Anna's Faculty Hospital (FNuSA), Brno, Czech Republic. All the participants were properly acquainted with the aim of the research, its methods and measuring procedures, and they consequently gave their informed consent in writing, as approved by the Ethical Committee of FNuSA. The inclusion criteria were unilateral primary osteoarthrosis without other orthopedic complications in the area of lower limbs and the spine, age between 40 and 65 years and participation in all three measurement sessions. In order to ensure the homogeneity of the treatment group, individuals were selected by the same orthopedist based on an examination of X-ray images. From a total of 32 patients 10 males met these criteria. Their age range was $54.1 \pm 7.5$ years, their average weight $92.2 \pm 9.6 \mathrm{~kg}$, average height $-179.7 \pm 5.9 \mathrm{~cm}$ and average BMI $-28.6 \pm 3.2 \mathrm{~kg} / \mathrm{m}^{2}$. These patients underwent the hip joint surgery between October 2016 and September 2017. The surgery was conducted with the patients in the supine position using the WatsonJones anterolateral approach involving a disinsertion of the gluteus medius muscle and gluteus minimus muscle from the greater trochanter. On average, the pa- cle from the greater trochanter. On average, the patients were transferred to the department of rehabilitation 8 days after the operation, where they were given intensive post-operative care for a further 14 days. The operation was according to needs followed by circa 6-8 weeks long post-operative regime of partial weight-bearing on crutches. After two months, the patients, depending on their tolerance levels, gradually discarded the crutches. All the patients had a noncemented artificial joint implanted, and their postoperative history was without complications.

\section{Experimental procedures and instruments}

Gait analysis was conducted three times: 20 days before the surgery, and 3 and 6 months after the surgery. The schedule of measurement sessions was set according to the orthopaedic check-ups with the physician. Measurements were taken in the Biomotor Laboratory of the Faculty of Sports Studies, Masaryk University in Brno in an area scanned by eight cameras of the Simi Motion system (Simi Reality Motion Systems GmbH, Unterschleissheim, Germany) (Fig. 1). Reflexive markers were placed at specific points on the patients' both lower limbs (the first metatarsal, outer ankle, the proximal head of the fibula and the greater trochanter of the thigh bone). Three trials were recorded at each measurement session, with each trial consisting of three gait cycles (strides), with only the last of the three trials being used for analysis, the first two trials were performed to get used to the movement in the laboratory conditions. Measurements were analysed using Simi Motion software, in which a 3D model of the patients' gait was created and then used to obtain the following parameters: the sagittal ranges of motion during walking in the ankle, knee and hip joints of both the operated and the unoperated limbs, the range of motion in the hip joints in the frontal plane, the rotation of the pelvis in the frontal and transverse planes, and the speed of walking and the length of steps.

\section{Statistical analysis}

Given the rather small number of participants (the sample size was not calculated as we included all the participants who met the inclusion criteria), we chose the Wilcoxon paired test for the statistical analysis, which demonstrated statistically significant changes with a coefficient of $p<0.05$. Data were described by mean, standard deviation, median and range. Furthermore, the changes in the individual parameters were compared using nonparametric Spearman correlation coefficients with the purpose of identifying relation- 


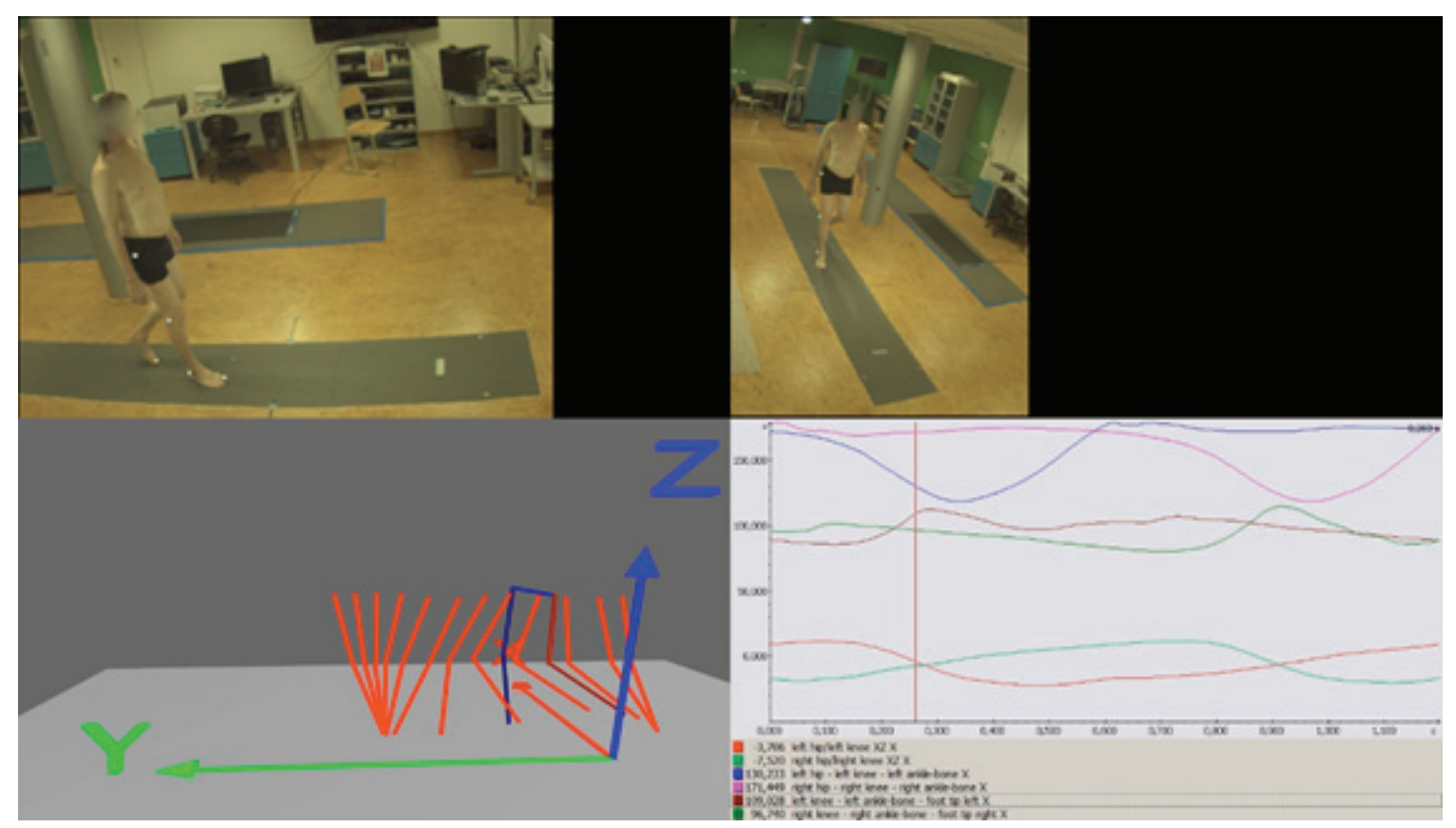

Fig. 1. Research data were collected using 3D kinematic analysis

ships. The results were considered statistically significant at the level of $p<0.05$. Analyses were performed using IBM SPSS Statistics 25.0.0 (IBM Corporation, 2017).

\section{Results}

Table 1 shows the measured data as averaged values, the standard deviation, median, range and the coefficient of statistical significance of changes compared with the initial values.

As can be seen in Fig. 2, the sagittal ROM in the affected hip during walking gradually increased after the surgery. Three months after the surgery the ROM was bigger in eight patients, and six months after the surgery the ROM had improved in nine patients. These changes were interpreted as statistically significant ( $p=0.047$ and 0.007 , respectively). The development of the sagittal range in the uninvolved hip, in both knees and in the ankle joint on the operated side varied among the patients and none of the changes in these areas was statistically significant. The ankle joint ROM on the uninvolved side was increased in eight patients in both measurement sessions after the operation. These increases were assessed as statistically significant with $p=0.022$ and 0.028 , respectively.

A gradual increase in step length was found in the unoperated limb of seven and eight patients in the first and the second follow-ups, respectively (Fig. 3). The step lengthening in the healthy limb over six months post-surgery was statistically significant ( $p=0.047$ ). Changes in the step length in the operated limb between measurement sessions were largely inconsistent and without statistical significance.

Changes in the rest of the measured parameters lacked any statistical significance, however some of the indicated tendencies might be interesting: the abduction-adduction range of the hip joint increased in the course of 6 months after the surgery on the operated side in seven patients and decreased on the unoperated side in eight patients (Fig. 4). However, the differences were so small that they were not statistically significant.

The rotation of the pelvis in the frontal plane, i.e. the vertical movement of the hips, decreased in 7 cases within the first three months after surgery, yet in the following three months it increased in the same number of patients (Fig. 4) and none of the changes was statistically significant.

The rotation of the pelvis in the transverse plane, that is, the horizontal movement of the hips, increased slightly in 7 patients six months after surgery (Fig. 4); however, the changes are small and the changes have no statistical significance.

Measurements showed that walking speed of 7 patients six months after the operation increased slightly (Fig. 4), but, according to the Wilcoxon test, the increases in our study were not statistically significant. 
Table 1. Changes of Selected Parameters from Baseline

\begin{tabular}{|c|c|c|c|c|c|c|c|c|}
\hline \multirow[b]{2}{*}{ Variables } & \multicolumn{2}{|c|}{ Baseline } & \multicolumn{2}{|c|}{$1^{\text {st }}$ follow-up } & \multirow[b]{2}{*}{$p$} & \multicolumn{2}{|c|}{$2^{\text {nd }}$ follow-up } & \multirow[b]{2}{*}{$p$} \\
\hline & Mean (SD) & $\begin{array}{c}\text { Median } \\
(\min ; \max ) \\
\end{array}$ & Mean (SD) & $\begin{array}{c}\text { Median } \\
(\min ; \max ) \\
\end{array}$ & & Mean (SD) & $\begin{array}{c}\text { Median } \\
(\min ; \max ) \\
\end{array}$ & \\
\hline $\begin{array}{l}\text { Operated hip sagittal } \\
\text { range }\end{array}$ & $25.10(5.11)$ & $26.1(14.4 ; 30.6)$ & $27.82(4.82)$ & $28.0(20.0 ; 34.1)$ & 0.047 & $30.03(3.02)$ & $30.0(24.5 ; 33.9)$ & 0.007 \\
\hline $\begin{array}{l}\text { Healthy hip sagittal } \\
\text { range }\end{array}$ & $32.11(4.85)$ & $34.5(25.2 ; 37.5)$ & $30.44(5.00)$ & $31.9(23.1 ; 38.1)$ & 0.059 & $31.54(3.47)$ & $32.2(26.5 ; 37.1)$ & 0.575 \\
\hline Operated knee range & $53.03(4.70)$ & $52.9(46.7 ; 61.0)$ & $53.29(6.34)$ & $54.0(43.1 ; 62.6)$ & 0.721 & $54.53(7.64)$ & $57.4(38.3 ; 62.2)$ & 0.445 \\
\hline Healthy knee range & $56.92(5.93)$ & $57.8(41.3 ; 62.0)$ & $57.53(4.88)$ & $58.3(48.6 ; 64.0)$ & 0.878 & $57.22(5.63)$ & $57.8(47.1 ; 65.6)$ & 0.959 \\
\hline Operated ankle range & $24.48(4.11)$ & $23.9(20.3 ; 31.1)$ & $24.35(3.36)$ & $24.7(19.4 ; 28.6)$ & 0.799 & $24.65(5.22)$ & $23.7(18.9 ; 34.6)$ & 0.959 \\
\hline Healthy ankle range & $24.30(4.37)$ & $24.8(15.9 ; 31.9)$ & $27.15(3.85)$ & $27.7(18.5 ; 33.1)$ & 0.022 & $27.37(5.16)$ & $27.0(19.9 ; 35.8)$ & 0.028 \\
\hline $\begin{array}{l}\text { Operated hip range } \\
\text { in frontal plane }\end{array}$ & $7.76(2.33)$ & $7.2(5.2 ; 13.0)$ & $7.32(2.48)$ & $7.1(4.2 ; 11.2)$ & 0.959 & $8.61(2.19)$ & $8.7(5.7 ; 12.7)$ & 0.203 \\
\hline $\begin{array}{l}\text { Healthy hip range } \\
\text { in frontal plane }\end{array}$ & $9.61(1.90)$ & $9.8(6.4 ; 11.9)$ & $8.47(1.33)$ & $8.4(6.4 ; 10.7)$ & 0.169 & $9.25(1.71)$ & $9.5(5.7 ; 11.2)$ & 0.285 \\
\hline Step length operated & $60.99(5.99)$ & $58.3(54.7 ; 72.5)$ & $57.68(7.14)$ & $57.6(45.9 ; 67.6)$ & 0.333 & $59.77(4.60)$ & $58.3(55.6 ; 69.5)$ & 0.799 \\
\hline Step length healthy & $56.03(5.23)$ & $53.7(50.2 ; 66.3)$ & $60.49(5.71)$ & $59.3(48.6 ; 68.2)$ & 0.093 & $61.07(5.62)$ & $61.2(48.7 ; 67.9)$ & 0.047 \\
\hline $\begin{array}{l}\text { Hip rotation in frontal } \\
\text { plane }\end{array}$ & $4.48(0.81)$ & $4.2(3.6 ; 6.0)$ & $4.06(1.33)$ & $4.0(2.1 ; 7.0)$ & 0.285 & $4.92(1.76)$ & $4.9(2.8 ; 9.0)$ & 0.646 \\
\hline $\begin{array}{l}\text { Hip rotation } \\
\text { in transversal plane }\end{array}$ & $14.75(5.63)$ & $14.8(6.9 ; 22.0)$ & $14.83(5.89)$ & $15.1(4.4 ; 22.0)$ & 0.878 & $14.42(4.25)$ & $13.8(7.1 ; 20.0)$ & 0.508 \\
\hline Velocity $[\mathrm{km} / \mathrm{h}]$ & $3.57(0.39)$ & $3.5(2.9 ; 4.2)$ & $3.61(0.44)$ & $3.6(2.9 ; 4.6)$ & 0.878 & $3.83(0.47)$ & $3.7(3.3 ; 4.8)$ & 0.059 \\
\hline
\end{tabular}

Data are described by mean, standard deviation, median and range, statistical significance of change from baseline was tested by Wilcoxon paired test.

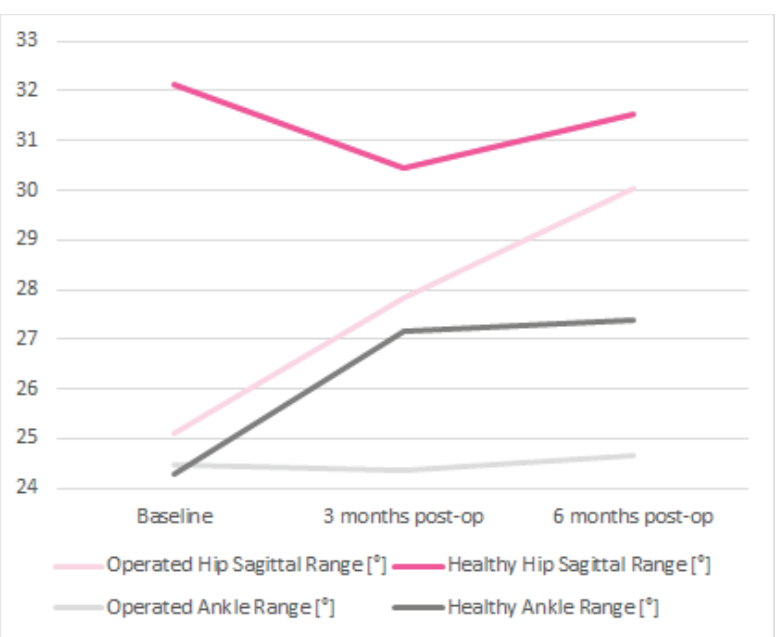

Fig. 2. Changes of hips and ankles sagital motion ranges

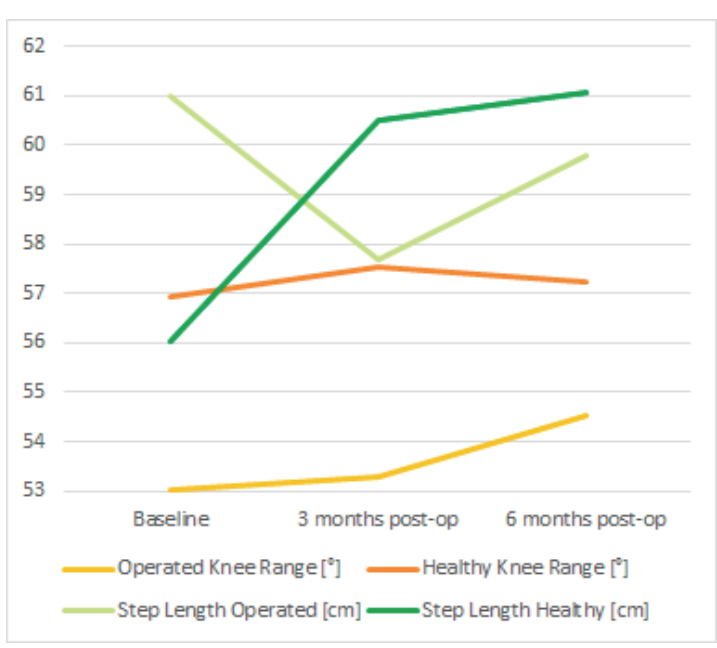

Fig. 3. Changes of knee motion ranges and step lengths

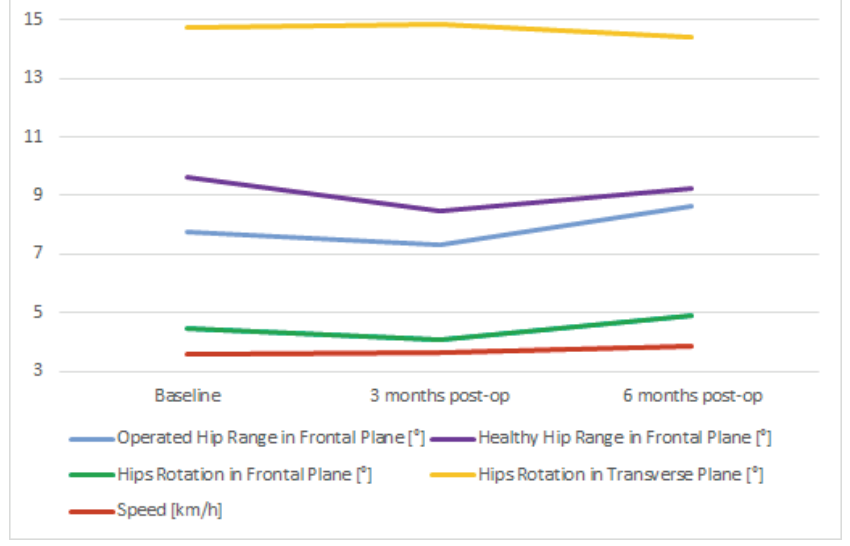

Fig. 4. Changes of hips and pelvis motion ranges and gait speed

The fact that one of the most marked changes was the increase in the sagittal range of motion in the operated hip joint and the increased step length in the healthy limb suggests that there is a mutual relationship between these changes and also a relationship with other increasing parameter values. The correlation coefficient (Table 2) between the increase in the sagittal range of motion in the operated hip and the increase in the step length in the unoperated limb is ( $r$ $=0.8 ; p=0.008)$. The same correlation coefficient was found between increases in the sagittal ROM in the operated and the unoperated hip joints $(r=0.8 ; p$ $=0.011)$. With the increasing range in the knee joint, the step length in that limb increased, and the correlation coefficients for the unoperated and the operated lower limbs were $(r=0.7 ; p=0.038)$ and $(r=0.6 ; p=$ $0.098)$, respectively. The increase in ankle ROM on 
Table 2. Correlation matrix of variables

\begin{tabular}{|c|c|c|c|c|c|c|c|c|c|c|c|c|c|}
\hline Variables & [1] & [2] & [3] & [4] & [5] & [6] & [7] & [8] & [9] & [10] & [11] & [12] & [13] \\
\hline $\begin{array}{l}\text { Operated hip sagital } \\
\text { range change }\end{array}$ & 1 & & & & & & & & & & & & \\
\hline $\begin{array}{l}\text { Unoperated hip sagital } \\
\text { range change }\end{array}$ & $0.758^{*}$ & 1 & & & & & & & & & & & \\
\hline $\begin{array}{l}\text { Operated knee range } \\
\text { change }\end{array}$ & 0.127 & -0.212 & 1 & & & & & & & & & & \\
\hline $\begin{array}{l}\text { Unoperated knee range } \\
\text { change }\end{array}$ & 0.442 & 0.491 & 0.491 & 1 & & & & & & & & & \\
\hline $\begin{array}{l}\text { Operated ankle range } \\
\text { change }\end{array}$ & 0.503 & 0.224 & 0.612 & 0.576 & 1 & & & & & & & & \\
\hline $\begin{array}{l}\text { Unoperated ankle range } \\
\text { change }\end{array}$ & 0.273 & 0.067 & 0.285 & 0.600 & 0.430 & 1 & & & & & & & \\
\hline $\begin{array}{l}\text { Operated hip range } \\
\text { in frontal plane change }\end{array}$ & 0.018 & -0.103 & -0.200 & 0.042 & -0.285 & 0.115 & 1 & & & & & & \\
\hline $\begin{array}{l}\text { Unoperated hip range } \\
\text { in frontal plane change }\end{array}$ & -0.370 & -0.236 & -0.455 & -0.321 & -0.212 & -0.394 & 0.467 & 1 & & & & & \\
\hline $\begin{array}{l}\text { Step length operated } \\
\text { change }\end{array}$ & 0.358 & -0.236 & 0.552 & 0.164 & 0.382 & 0.224 & 0.382 & -0.055 & 1 & & & & \\
\hline $\begin{array}{l}\text { Step length unoperated } \\
\text { change }\end{array}$ & $0.782 * *$ & 0.430 & 0.576 & $0.661^{*}$ & $0.758^{*}$ & 0.479 & 0.103 & -0.321 & 0.503 & 1 & & & \\
\hline $\begin{array}{l}\text { Hip rotation in frontal } \\
\text { plane change }\end{array}$ & 0.321 & 0.055 & 0.394 & 0.418 & $0.758^{*}$ & 0.612 & -0.224 & -0.042 & 0.224 & 0.612 & 1 & & \\
\hline $\begin{array}{l}\text { Hip rotation in transversal } \\
\text { plane change }\end{array}$ & -0.491 & $-0.661 *$ & 0.079 & -0.200 & -0.055 & -0.006 & 0.103 & 0.321 & 0.406 & -0.430 & -0.067 & 1 & \\
\hline Speed change & 0.515 & 0.091 & $0.685^{*}$ & 0.321 & 0.358 & 0.164 & 0.127 & -0.321 & $0.721 *$ & $0.685^{*}$ & 0.309 & -0.164 & 1 \\
\hline
\end{tabular}

$$
* p<0.05, * * p<0.01
$$

the operated side can also positively affect the step length of the unoperated limb $(r=0.8 ; p=0.011)$. The hip rotations in the frontal plane are also connected to the range of motion at the ankle on the operated side: the greater the range of motion at the ankle, the greater the vertical movements of the hips $(r=0.8$; $p=0.011)$. The hips rotation in the transverse plane seems to be indirectly proportional to the range of the sagittal movement in the hips $(r=-0.7 ; p=0.038)$ in the unoperated hip and $(r=-0.5 ; p=0.150)$ in the operated hip.

\section{Discussion}

In agreement with results of other studies [14], [20], we found the gradual increase of the sagittal range of motion in the operated hip joint. Given the fact that the hip range of motion in the sagittal plane during walking in people with arthrosis of the hip is smaller than it is in healthy people [13], [16], the increase in range is an undoubted success of THR. The indicated increase in the abduction-adduction range of the operated hip in the majority of our patients is in agreement with the study by Zeni et al. [20] and, in view of the generally decreased range in comparison with healthy people [2], indicates a positive change.
Regarding the sagittal ROM in the unoperated hip, one study reported a lower ROM in arthritic patients in comparison with the control group [5], while another study reported a greater range in patients with arthrosis, probably compensating for the insufficient sagittal ROM in the hip joint with arthrosis [10]. Our analysis, which found a positive correlation in sagittal range changes between the operated and the unoperated hips, agrees more closely with the measurements made by Ornetti et al. [16], where a post-surgery increase in the unoperated hip ROM would have been expected in parallel with an increase of the ROM in the operated hip. Apart from these diverse pieces of information concerning the ROM before the operation, the reference studies [1], [2], [6] [9], [16], [19], [20] make no mention of any statistically significant changes in this parameter after the operation, and no statistically significant changes were discovered in our research, either. Beaulieu et al. [1] drew attention to the fact that adduction in the contralateral hip of the THR patients in the frontal plane is reduced compared with the healthy group, and we, too, predominantly recorded a decrease in the abduction-adduction range in the majority of our patients.

While the sagittal range of the contralateral knee in patients with arthrosis was greater before the operation [10], decreased ranges of motion in both knees 
were found after THR compared to healthy peers [9]. In the context of post-surgical improvements, we expected gradual increases in the ROM in the knees. Although the average values obtained in our research indicate such a tendency, no improvements found in our or any other reference studies [1], [2], [6], [19], [20] were statistically significant.

In comparison with the control group, Ornetti [16] discovered increased dorsal flexion in both limbs of the patients who had undergone unilateral hip replacement surgery. The significantly increased range in the sagittal plane in the ankle joint on the unoperated side, which we found in our patients during both post-operative measurement sessions, is thus in agreement with the aforementioned study.

The step length in people with arthrosis was shorter both before and after the operation than in the healthy control group [5], [16]. The gradual step lengthening in patients we anticipated as a result of the surgical intervention was confirmed in our research on the unoperated limb. According to the correlation coefficients from our analysis, the step length in the unoperated limb is affected by the sagittal ranges of the hip and ankle joints on the operated side, and the range of motion of the knee joint on the unoperated side. The increase in range of the contralateral joints bearing weight during the swing phase certainly prolongs the duration of this phase, thanks to which the step can be longer. The increase in the ipsilateral knee ROM increases the possible spatial component of gait cycle achievable during the swing phase. The same relationship between the knee ROM and the step length was recorded in the operated limb.

The rotation of the pelvis in the frontal plane was greater in patients with arthrosis [21], but reference studies [2], [6] [9], [16], [20] make no mention of the state after THR. The decrease of rotations, which was tentatively suggested in our study during the first follow-up measurement, ought to have been a good sign, however, further development in this direction was not overly positive. Correlation analysis links the rotation of the pelvis in the frontal plane with the range of motion in the ankle joint on the operated side, i.e., the transfer of the vertical motion of the ankle up to the hip level. However, no clear postoperative changes either in the ankles or in the rotation of the pelvis emerged from the studies [1], [2], [6] [9], [16], [19]-[21], so we are unable to verify adequately this relationship.

The rotation of the hips in the transverse plane in patients who had undergone lateral approach THR was increased in comparison with healthy people [10], and even during the second measurement session after the operation we observed moderate increase in the majority of patients. However, the carried out correlation analysis links the rotation of the hips in the transverse plane in indirect proportion to the range of sagittal motion in the hips. So the decreased range in the hips is compensated for by the greater forward-backward motion of the hips and, conversely, with greater sagittal range in the hip, as was discovered during our research, the rotations of the pelvis in the transverse plane ought to decrease.

In patients with arthrosis [21] and in patients who had undergone THR [2] a reduced walking speed was discovered. After the operation an increase in speed was recorded [20], which is in accordance with the indicated trend in our patients.

\section{Conclusions}

Although research has revealed significant differences in kinematic parameters of gait in patients who had undergone THR from the gait of their healthy peers one year [6] or even 10 years [2] post-surgery, the positive effect of the operation on the quality of the patient's life and on their gait pattern is indisputable. From the kinematic point of view, to which our study was devoted, we found that after the surgery the sagittal range of motion in the affected hip joint in particular was corrected. This was accompanied by a lengthening of the step and increase in the sagittal range of motion in the ankle both in the unoperated limb. In our research, we have also pointed to several interesting connections between changes of the parameters at various places in the lower limbs, such as direct proportion between the range of motion in the sagittal plane on the operated joint and length of the step of the unoperated lower limb and other less statistically significant relations, but it should be verified on a larger sample of subjects. Knowledge of these changes and relationships might be useful in the rehabilitation period of the patients after THR.

\section{Study limitations}

The most important limitation lies clearly in the low number of participants who met the inclusion criteria. That is why there were so little of significant results and also the statistical significance in such a small group is quite weak. Also, measurement after a longer period after the surgery would provide interesting data. This might be an inducement for a further larger study. 


\section{Acknowledgements}

Petr Huta, Department of Kinesiology, Faculty of Sports Studies, Masaryk University: measurements. Jan Švancara, Institute of Biostatistics and Analyses, Masaryk University: statistics. Ota Brídl, BOKS s. r. o.: translation.

\section{Conflict of interest}

The authors declare that there is no potential conflict of interest relevant to this article.

\section{References}

[1] Beaulieu M.L., Lamontagne M., Beaulé P.E., Lower limb biomechanics during gait do not return to normal following total hip arthroplasty, Gait Posture, 2010, 32 (2), 269-275.

[2] Bennett D., Humphreys L., O’Brien S., Kelly C., OrR J.F., BEVERLAND D.E., Gait kinematics of age-stratified hip replacement patients - A large scale, long-term follow-up study, Gait Posture, 2008, 28 (2), 194-197.

[3] Bennett D., Ogonda L., Elliott D., Humphreys L., Beverland D.E., Comparison of gait kinematics in patients receiving minimally invasive and traditional hip replacement surgery: A prospective blinded study, Gait Posture, 2006, 23 (3), 374-382.

[4] Bennett D., Ryan P., O’Brien S., Beverland D.E., Gait kinetics of total hip replacement patients-A large scale, longterm follow-up study, Gait Posture, 2017, 53, 173-178.

[5] Constantinou M., Loureiro A., Carty Ch., Mills P., BARRETT R., Hip joint mechanics during walking in individuals with mild-to-moderate hip osteoarthritis, Gait Posture, 2017, 53, 162-165.

[6] Foucher K.C., Hurwitz D.E., Wimmer M.A., Preoperative gait adaptations persist one year after surgery in clinically well-functioning total hip replacement patients, J. Biomech., 2007, 40 (15), 3432-3437.

[7] Gallo J., Orthopedics for students of medical and health faculties, Palacký University in Olomouc [Ortopedie pro studenty lékařských a zdravotnických fakult, Univerzita Palackého v Olomouci], 2011.

[8] Hart R., Rozkydal Z., Long term results with THA Poldi [Dlouhodobé výsledky totální endoprotézy kyčelního kloubu Poldi], Acta Chir. Orthop. Tr., 1999, 66, 139-146.
[9] Horstmann T., Listringhaus R., HaAse G.B., Grau S., MÜNDERMANN A., Changes in gait patterns and muscle activity following total hip arthroplasty: A six-month follow-up, Clin. Biomech., 2013, 28 (7), 762-769.

[10] KISS R.M., ILlyÉs Á., Comparison of gait parameters in patients following total hip arthroplasty with a direct-lateral or antero-lateral surgical approach, Hum. Movement Sci., 2012, 31 (5), 1302-1315.

[11] Koudela K., Ortopedie, Karolinum, 2004.

[12] LeE J.M., The Current Concepts of Total Hip Arthroplasty, Hip Pelvis, 2016, 28 (4), 191-200.

[13] LeIGH R.J., OsIS S.T., Ferber R., Kinematic gait patterns and their relationship to pain in mild-to-moderate hip osteoarthritis, Clin. Biomech., 2016, 34, 12-15.

[14] Mazzoli D., Giannotti E., Longhi M., Prati P., Masiero S., Merlo A., Age explains limited hip extension recovery at one year from total hip arthroplasty, Clin. Biomech., 2017, 48, 35-41.

[15] Musil D., Contribution of Minimally Invasive Total Hip Replacement - MIS-AL, Health and Social Aspects of MIS-AL Approach, С̆. Bud., 2011. dissertation (Ph.D.). University of South Bohemia in České Budějovice. Faculty of Health and Social Science. [Př́nos miniinvazivní MIS-AL techniky při implantaci totální náhrady kyčelního kloubu, zdravotně sociální aspekty MIS-AL př́stupu, Č. Bud., 2011. disertační práce (Ph.D.). JIHOČESKÁ UNIVERZITA V ČESKÝCH BUDĚJOVICÍCH. Zdravotně sociální fakulta].

[16] ORnetti P., LaRoche D., Morisset C., Beis J.N., TAVERNIER C., MAILlefert J.F., Three-dimensional kinematics of the lower limbs in hip osteoarthritis during walking, J. Back Musculoskelet., 2011, 24 (4), 201-207.

[17] Renkawitz T., Weber T., Dullien S., Woerner M., DENDORFER S., GRIFKA J., WeBER M., Leg length and offset differences above $5 \mathrm{~mm}$ after total hiparthroplasty are associated with altered gait kinematice, Gait Posture, 2016, 49, 196-201.

[18] Tsai T.Y., Dimitriou D., Li J.S., Woo Nam K., Li G., KwON Y.M., Asymmetric hip kinematics during gait in patients with unilateral total hip arthroplasty: In vivo 3-dimensional motion analysis, J. Biomech., 2015, 48 (4), 555-559.

[19] Wesseling M., Meyer C., Corten K., Desloovere K., JONKERS I., Longitudinal joint loading in patients before and up to one year after unilateral total hip arthroplasty, Gait Posture, 2018, 61, 117-124.

[20] Zeni J., Madara K., WitMer H., Gerhardt R., Rubano J., The effect of surgical approach on gait mechanics after total hiparthroplasty, J. Electromyogr. Kines., 2018, 38, 28-36.

[21] Zeni J., PozZi F., ABujaber S., Miller L., Relationship between physical impairments and movement patterns during gait in patients with end-stage hip osteoarthritis, J. Orthop. Res., 2015, 33 (3), 382-389. 